\title{
Analytical Solution for the Ultimate Strength of Sandwich Panels under In-plane Compression and Lateral Pressure
}

\author{
Bong Ju Kim $\circledast^{*}$ \\ "The Korea Ship and Offshore Research Institute, Pusan National University, Busan, Korea \\ 조합 하중을 받은 샌드위치 패널의 최종강도 설계식 개발 \\ 김봉주(10* \\ "부산대학교 선박해양플랜트기술연구원
}

KEY WORDS: Ultimate strength 최종강도, Analytical solution 해석해, Sandwich panel 샌드위치 패널, In-plane compression 면내 압축, Lateral pressure 횡압력, Clamped boundary condition 고정단 경계조건

\begin{abstract}
The paper presents a closed-form analytical solution for the ultimate strength of sandwich panels with metal faces and an elastic isotropic core during combined in-plane compression and lateral pressure under clamped boundary condition. By using the principle of minimum potential eneroy, the stress distribution in the faces during uni-axial edge compression and constant lateral pressure was obtained. Then, the ultimate edge compression was derived on the basis that collapse occurs when yield has spread from the mid-length of the sides of the face plates to the center of the convex face plates. The results were validated by nonlinear finite element analysis. Because the solution is analytical and closed-form, it is rapid and efficient and is well-suited for use in practical structural design methods, including repetitive use in structural optimization. The solution applies for any elastic isotropic core material, but the application that stimulated this study was an elastomer-cored steel sandwich panel that had excellent energy absorbing and protective properties against fire, collisions, ballistic projectiles, and explosions.
\end{abstract}

\section{1. 서 론}

샌드위치 패널(Sandwich panel)은 일반적으로 밀도가 낮은 심 재(Core)의 양면에 얇은 면재(Face plate)를 붙여서 제작되며 기 계적 강도 특성이 우수하고 구조경량화가 용이하여 다양한 산 업현장에서 활용되고 있다. 심재와 면재는 매우 다양하며 심재 는 벌집모양(Honeycomb) 등으로 빈공간이 있는 형태 또는 빈공 간이 없는(Solid filling) 형태로 제작된다(Wikipedia, 2019a). Sandwich plate system(SPS)으로 알려진 두장의 강판 사이에 폴 리우레탄계열의 탄성체(Polyurethane elastomer)를 주입하여 제작 되는 샌드위치 패널이 그 대표적인 사례이다(Wikipedia, 2019b). Fig. 1에서 볼 수 있듯이 샌드위치 패널 구조는 보강판 구조에 비해 보강재의 개수를 줄일 수 있어 구조 경량화와 더불어 구 조 단순화에 큰 장점이 있다. 최근 20 여년간 선박 및 해양플랜 트 설비에 샌드위치 패널 구조의 적용이 점차 증가되고 있으며 국제선급협회에서는 이에 대한 설계지침 개발을 위해 노력하고 있다(DNV-GL, 2016; LR, 2019).

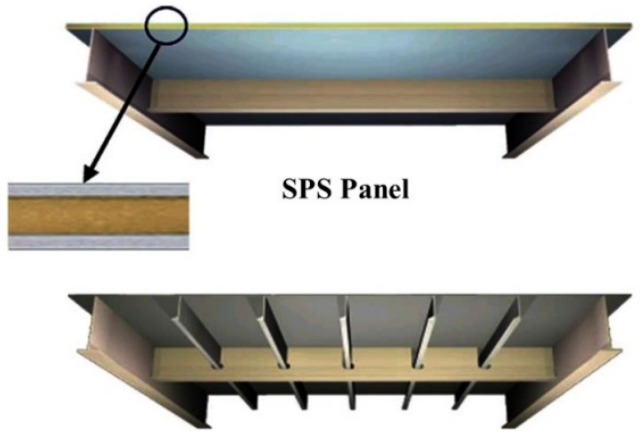

Conventional Stiffened Panel

Fig. 1 A general structure arranement of sandwich panels and conventioal stiffened panels (SPS Technology, 2019)

본 연구에서는 직사각형 샌드위치 패널에 횡압력(Lateral pressure) 과 면내 압축(In-plane compression)이 작용할 경우에 대한 최종 강도 설계식을 개발하고자 한다. 설계현장에서 유용하게 활용

Received 3 October 2019, revised 29 October 2019, accepted 30 October 2019

Corresponding author Bong Ju Kim: +82-51-510-2338, bonjour@pusan.ac.kr ORCID: https://orcid.org/0000-0002-8234-1030

(c) 2019, The Korean Society of Ocean Engineers

This is an open access article distributed under the terms of the creative commons attribution non-commercial license (http://creativecommons.org/licenses/by-nc/3.0) which permits unrestricted non-commercial use, distribution, and reproduction in any medium, provided the original work is properly cited. 
될 수 있도록 명시적인 형태의 해석해를 도출하였으며, 비선형 유한요소해석 결과와의 비교를 통해 그 적용 가능성을 검증하 였다.

\section{2. 샌드위치 패널의 정식화}

선체 보강판 구조에 작용하는 하중 특성을 살펴보면 적재화 물 및 수압으로 인해 횡압력을 그리고 굽힘 또는 비틀림 모멘 트로 인해 면내 하중, 즉 면내 인장압축 또는 전단 하중을 받는 다. 선저부 또는 화물창 바닥과 같이 횡압력이 비교적 크게 작 용하는 보강판 구조의 경계조건은 작용하는 횡압력의 크기가 증가함에 따라 판의 모서리 방향의 회전구속이 증가하여 회전 이 완전 구속된 고정단 경계조건(Clamped boundary condition)이 되며 이는 응력분포 및 최종강도에 영향이 크다고 알려져 있다 (Paik, 2018).

Riber(1997)는 최소 포텐셜 에너지 원리(Principle of minimum potential energy)를 적용하여 횡압력이 작용하는 샌드위치 패널 의 해석해를 도출한 바 있다. 패널 경계의 회전이 자유로운 단 순지지조건(Simply supported bounday condition)과 회전이 구속 되는 고정단 경계조건(Clamped boundary condition)에 대하여 각 각 도출된 해석해는 단순지지조건인 경우에는 횡처짐과 변형율 이 수치해석결과와 비교적 잘 일치하지만, 고정단 경계조건인 경우는 경계부근의 횡처짐과 변형율이 과소평가됨을 규명하였 으며 해석해를 도출할 때 횡처짐 가정함수의 항의 개수가 횡처 짐 거동을 충분히 묘사할 수 있도록 충분한 개수를 고려할 것 을 강조하였다. 그리고 횡처짐 가정함수의 항의 개수가 증가할 수록 대처짐 비선형 판이론을 적용하여 복잡한 비선형 연립방 정식 형태의 해석해를 얻는 것보다 선형 판이론을 사용하여 선 형 연립방정식 형태의 해석해를 도출하는 것이 보다 합리적인 방법임을 제안하였다. Noor et al.(1996) 역시 일반적인 샌드위치 패널의 전체거동(Global response)은 일차전단변형 판이론 (First-order shear deformation plate theory)과 미소처짐이론(Small deflection theory)으로도 충분히 정확한 해석이 가능함을 연구결 론에서 밝힌 바가 있다.

본 연구에서는 Fig. 2에서 도시하고 있는 횡압력과 면내압축 하중을 받는 샌드위치 패널의 최종강도 설계식을 개발하기 위 해서 일차전단변형모델과 미소처짐이론을 사용하였으며, 패널

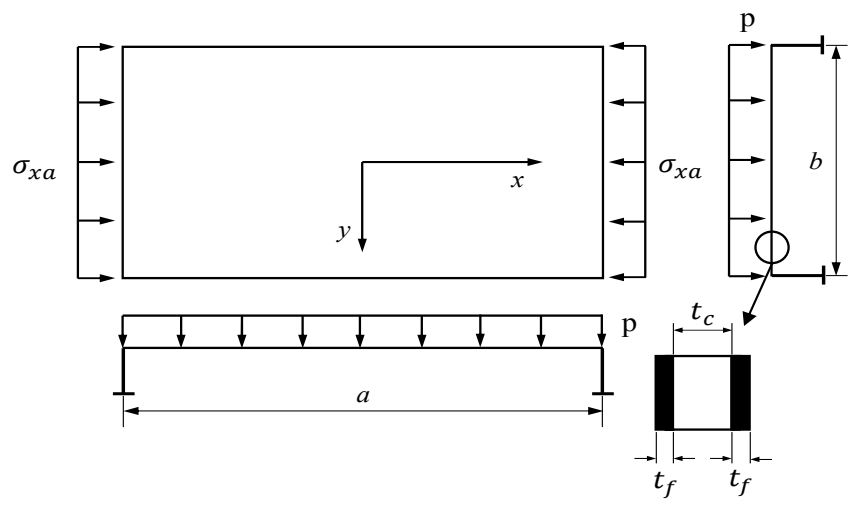

Fig. 2 A retangular sandwich panel under in-plane compression and lateral pressure loads
4면의 경계조건을 고정단 경계조건으로 채택하였다. 그리고 (1) 심재와 면재의 두께는 일정하고, (2) 재료는 선형 탄성거동을 하는 등방성 재료이며, (3) 두께 방향으로 비압축성이고, (4) 패 널은 중립면에 대해서 대칭이며, (5) 면재의 두께는 얇아서 키 르히호프-러브의 가정(Kirchhoff-Love hypotheses)을 수용가능하 고, (6) 심재는 면외전단력(Transverse shear force)만 전달하며, (7) 심재 두께방향의 면외전단력은 동일하며, (8) 심재와 면재는 완벽하게 결합이되어 있다고 가정하였다.

\section{1 전체 포텐셜 에너지(Total potential energy)}

고전적인 선형 판이론(Kirchhoff-Love plate theory)에 면외전단 효과를 고려한 일차전단변형 판이론에서 변위장(Displacement field)은 Fig. 3 과 같으며 아래의 식과 같이 정의된다(Reddy, 2003).

$$
\begin{aligned}
& u(x, y, z)=\bar{u}(x, y)+z\left\{\gamma_{x z}(x, y)-\frac{\partial \bar{w}(x, y)}{\partial x}\right\} \\
& v(x, y, z)=\bar{v}(x, y)+z\left\{\gamma_{y z}(x, y)-\frac{\partial \bar{w}(x, y)}{\partial y}\right\}
\end{aligned}
$$

$w(x, y, z)=\bar{w}(x, y)$

여기서, $\bar{u}, \bar{v}, \bar{w}$ 는 각각 판의 중립면에서 길이, 폭, 횡처짐 방향 의 변위성분이고, $\gamma_{x z}$ 와 $\gamma_{y z}$ 는 면외전단 변형률이다.

식 (1)-(3)과 전술한 기본 가정을 활용하면 샌드위치 패널의 구성방정식(Constitutive equations)은 다음과 같다.

$$
\begin{aligned}
& \left\{\begin{array}{l}
N_{x} \\
N_{y} \\
N_{x y}
\end{array}\right\}=\left[\begin{array}{ccc}
A_{11} & A_{12} & 0 \\
A_{12} & A_{22} & 0 \\
0 & 0 & A_{66}
\end{array}\right]\left\{\begin{array}{c}
\frac{\partial \bar{u}}{\partial x} \\
\frac{\partial \bar{v}}{\partial y} \\
\frac{\partial \bar{u}}{\partial x}+\frac{\partial \bar{v}}{\partial y}
\end{array}\right\} \\
& \left\{\begin{array}{c}
Q_{x} \\
Q_{y}
\end{array}\right\}=\left[\begin{array}{cc}
A_{55} & 0 \\
0 & A_{44}
\end{array}\right]\left\{\begin{array}{l}
\gamma_{x z} \\
\gamma_{y z}
\end{array}\right\}
\end{aligned}
$$

$$
\left\{\begin{array}{c}
M_{x} \\
M_{y} \\
M_{x y}
\end{array}\right\}\left[\begin{array}{ccc}
D_{11} & D_{12} & 0 \\
D_{12} & D_{22} & 0 \\
0 & 0 & D_{66}
\end{array}\right]\left\{\begin{array}{c}
\frac{\partial \gamma_{x z}}{\partial x}-\frac{\partial^{2} \bar{w}}{\partial x^{2}} \\
\frac{\partial \gamma_{y z}}{\partial y}-\frac{\partial^{2} \bar{w}}{\partial y^{2}} \\
\frac{\partial \gamma_{x z}}{\partial y}+\frac{\partial \gamma_{y z}}{\partial x}-2 \frac{\partial^{2} w}{\partial x \partial y}
\end{array}\right\}
$$

여기서, $N_{x}, N_{y}, N_{x y}$ 는 면내 하중성분이고, $M_{x}, M_{y}, M_{x y}$ 는 모멘 트 성분이며, $Q_{x}, Q_{y}$ 는 면외전단력 성분으로 모두 단위길이당 작용하는 하중이다. 각 강성계수들은 아래와 같이 정의 되어진 다(Plantema, 1966; Vinson, 2005).

$$
\begin{aligned}
& A_{11}=A_{22}=2 E t_{f} /\left(1-v^{2}\right), \quad A_{12}=v A_{11}, \quad A_{66}=A_{11}(1-v) / 2 \\
& A_{44}=A_{55}=t_{c} G_{c} \\
& D_{11}=D_{22}=E t_{f}\left(3 t_{c}^{2}+6 t_{c} t_{f}+4 t_{f}^{2}\right) / 6\left(1-v^{2}\right) \\
& D_{12}=v D_{11}, \quad D_{66}=D_{11}(1-v) / 2
\end{aligned}
$$

여기서, $t_{f}, t_{c}$ 는 면재와 심재의 두께, $E, v$ 는 면재의 탄성계수 및 프와송비, $G_{c}\left(=E_{c} / 2\left(1+v_{c}\right)\right)$ 는 심재의 전단탄성계수이다. 
Analytical Solution for the Ultimate Strength of Sandwich Panels under In-plane Compression and Lateral Pressure 537

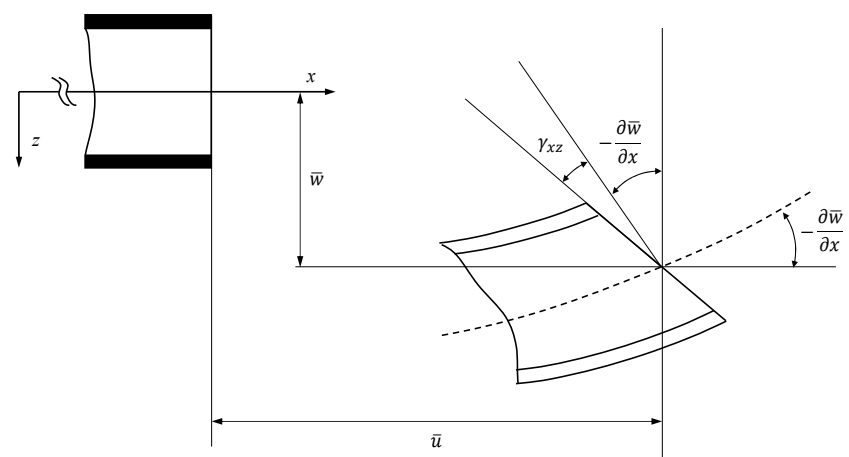

Fig. 3 Deformation of sandwich panels acoording to first-order shear deformation plate theory

횡압력 $p$ 와 면내압축 하중 $N_{x a}$ 의 조합하중을 받는 샌드위치 패널의 전체 포테셜 에너지는 식 (4)-(9)를 활용하면 다음과 같 이 구할 수 있다

$$
\Pi=U+V
$$

여기서, $U$ 는 변형률 에너지, $V$ 는 작용하중에 의한 포텐셜 에너 지이고 각각은 다음과 같이 나타낼 수 있다.

$$
\begin{aligned}
& U=\frac{1}{2} \iint\left\{A_{11}\left(\frac{\partial \bar{u}}{\partial x}\right)^{2}+A_{22}\left(\frac{\partial \bar{v}}{\partial y}\right)^{2}+A_{66}\left(\frac{\partial \bar{u}}{\partial y}+\frac{\partial \bar{v}}{\partial x}\right)^{2}+2 A_{12} \frac{\partial \bar{u}}{\partial x} \frac{\partial \bar{v}}{\partial y}\right. \\
& +D_{11}\left(\frac{\partial \gamma_{x z}}{\partial x}-\frac{\partial^{2} \bar{w}}{\partial x^{2}}\right)^{2}+D_{22}\left(\frac{\partial \gamma_{y z}}{\partial y}-\frac{\partial^{2} \bar{w}}{\partial y^{2}}\right)^{2}+D_{66}\left(\frac{\partial \gamma_{x z}}{\partial y}+\frac{\partial \gamma_{y z}}{\partial x}-2 \frac{\partial^{2} \bar{w}}{\partial x \partial y}\right)^{2} \\
& \left.+2 D_{12}\left(\frac{\partial \gamma_{x z}}{\partial x}-\frac{\partial^{2} \bar{w}}{\partial x^{2}}\right)\left(\frac{\partial \gamma_{y z}}{\partial y}-\frac{\partial^{2} \bar{w}}{\partial y^{2}}\right)+A_{44} \gamma_{y z}^{2}+A_{55} \gamma_{x z}^{2}\right\} d x d y \\
& V=-\iint p w d x d y-\iint N_{x a}\left(\frac{\partial \bar{u}}{\partial x}+\frac{1}{2}\left(\frac{\partial \bar{w}}{\partial x}\right)^{2}\right\} d x d y(12)
\end{aligned}
$$

\section{2 경계조건과 변위함수}

에너지법을 적용하여 샌드위치 패널의 해석해를 도출하기 위 해서는 먼저 경계조건을 만족하는 적합한 근사적인 변위함수를 가정하여야 한다. 본 연구에서는 샌드위치 패널의 경계조건이 고정단 경계조건이므로 다음의 경계조건식을 만족하는 변위함 수가 필요하다.

$$
\begin{array}{ll}
\bar{w}=\frac{\partial \bar{w}}{\partial x}=\gamma_{x z}=0 & \text { at } x=-a / 2, a / 2 \\
\bar{w}=\frac{\partial \bar{w}}{\partial y}=\gamma_{y z}=0 & \text { at } y=-b / 2, b / 2
\end{array}
$$

여기서, $a$ 와 $b$ 는 Fig. 2 에서 나타내는 바와 같이 각각 패널의 길 이(Length)와 폭(Breadth)이며 샌드위치 패널의 중앙이 원점이 된다.

Mbakogu and Pavlovic(2000)은 아래와 같은 다항식을 활용하 여 횡압력을 받는 고정단 경계조건을 갖는 사각형판의 중앙부 최대 횡처짐량과 경계에서 굽힘 모멘트 및 면외전단력의 오차 를 분석하였다. $\bar{w}=\phi \sum_{i=0}^{\infty} \sum_{j=0}^{\infty} B_{i j} x^{i} y^{j}$

여기서, $\phi$ 는 $\left(x^{2}-\frac{a^{2}}{4}\right)^{2}\left(y^{2}-\frac{b^{2}}{4}\right)^{2}, B_{i j}$ 는 미지상수로 단항식 $\phi x^{i} y^{j}$ 의 크기(횡처짐량)를 나타내며, 에너지법을 적용하여 구해 야 하는 값이다. Mbakogu and Pavlovic(2000)은 횡압력으로 인해 횡처짐이 대칭으로 발생하기 때문에 $i$ 와 $j$ 가 0 또는 짝수인 항 을 사용하고, 판의 종횡비가 크지 않을 경우 $(a / b \leq 2), \phi, \phi x^{2}$ 그 리고 $\phi y^{2}$ 의 3 개의 단항식만 고려하여도 최대처짐량과 굽힘모멘 트 등의 오차가 크지 않음을 확인하였다. 본 연구에서는 여기에 $\phi x^{4}$ 과 $\phi y^{4}$ 의 단항식을 추가하여 총 5 개의 단항식으로 식 (16) 과 같이 횡처짐 변위함수를 가정하였다. 각 단항식의 미지상수 $\left(a_{1} \sim a_{5}\right)$ 는 전술한 바와 같이 에너지법을 적용하여 구해질 횡처 짐 변위의 크기이다. 중립면에서 길이, 폭방향의 변위성분은 Fig. 2의 면내압축 하중 $\left(\sigma_{x a}=N_{x a} / 2 t_{f}\right)$ 과 훅의 법칙을 이용하여 식 (17)과 식 (18)로 정의할 수 있고, 면외전단 변형률은 Fig. 3 에서 볼수 있듯이 $\frac{\partial \bar{w}}{\partial x}$ 가 증가하면 $\gamma_{x z}$ 도 증가할 것이므로 식 (16)의 횡처짐 변위함수를 편미분한 형태의 간단한 단항식으로 가정하여 각각 식 (19)과 식 (20)과 같이 가정하였다. 여기서 $a_{6}$ 과 $a_{7}$ 역시 에너지법을 적용하여 구해야 하는 면외전단 변형률 의 크기이다. 본 연구를 위해 가정된 변위함수들은 모두 식 (13) 과 식 (14)의 경계조건을 만족함을 알 수 있다.

$$
\begin{aligned}
& \bar{w}=\phi\left(a_{1}+a_{2} x^{2}+a_{3} y^{2}+a_{4} x^{4}+a_{5} y^{4}\right) \\
& \bar{u}=-\frac{N_{x a}}{2 t_{f} E} x \\
& \bar{v}=\frac{v N_{x a}}{2 t_{f} E} y
\end{aligned}
$$

$\gamma_{x z}=a_{6} \phi x$

$\gamma_{y z}=a_{7} \phi y$

\section{3 샌드위치 패널의 이론해석해}

식 (16)-(20)과 식 (10)-(12)를 사용하면 조합하중을 받는 고정 단 경계조건을 갖는 샌드위치 패널의 전체 포테셜 에너지를 구 할 수 있고 식 (21)과 같이 최소 포텐셜 에너지 원리를 적용하 면 총 7 개의 미지상수 $a_{i}$ 에 대한 7 개의 1 차 연립방정식 형태의 해석해를 구할 수가 있다. 가우스 소거법 등의 방법을 사용하여 연립방정식 풀면 7 개의 미지 상수 $a_{i}$ 를 결정할 수 가 있다. 즉, 작용하는 하중에 대한 횡처짐의 크기와 면외전단 변형률의 크 기를 결정할 수 있다.

$$
\frac{\partial(U+V)}{\partial a_{i}}=0
$$

식 (21)의 결과로 도출된 7 개의 1 차 연립방정식은 부록 (Appedix)에 첨부하였다. 
작용하는 하중에 대한 횡처짐의 크기와 면외전단 변형률의 크기가 결정되면 식 (22)-(25)과 같이 후크의 법칙을 활용하여 샌드위치 패널의 두 면재의 응력상태를 구할 수가 있다 (Plantema, 1966; Vinson, 2005).

$$
\begin{aligned}
& \sigma_{x 1}=\frac{E}{\left(1-v^{2}\right)}\left[\left(\frac{\partial \bar{u}}{\partial x}+v \frac{\partial \bar{v}}{\partial y}\right)+\frac{t_{c}+t_{f}}{2}\left\{\left(\frac{\partial \gamma_{x z}}{\partial x}-\frac{\partial^{2} \bar{w}}{\partial x^{2}}\right)+v\left(\frac{\partial \gamma_{y z}}{\partial y}-\frac{\partial^{2} \bar{w}}{\partial y^{2}}\right)\right\}\right] \\
& \sigma_{y 1}=\frac{E}{\left(1-v^{2}\right)}\left[\left(v \frac{\partial \bar{u}}{\partial x}+\frac{\partial \bar{v}}{\partial y}\right)+\frac{t_{c}+t_{f}}{2}\left\{v\left(\frac{\partial \gamma_{x z}}{\partial x}-\frac{\partial^{2} \bar{w}}{\partial x^{2}}\right)+\left(\frac{\partial \gamma_{y z}}{\partial y}-\frac{\partial^{2} \bar{w}}{\partial y^{2}}\right)\right\}\right] \\
& \sigma_{x 2}=\frac{E}{\left(1-v^{2}\right)}\left[\left(\frac{\partial \bar{u}}{\partial x}+v \frac{\partial \bar{v}}{\partial y}\right)-\frac{t_{c}+t_{f}}{2}\left\{\left(\frac{\partial \gamma_{x z}}{\partial x}-\frac{\partial^{2} \bar{w}}{\partial x^{2}}\right)+v\left(\frac{\partial \gamma_{y z}}{\partial y}-\frac{\partial^{2} \bar{w}}{\partial y^{2}}\right)\right\}\right] \\
& \sigma_{y 2}=\frac{E}{\left(1-v^{2}\right)}\left[\left(v \frac{\partial \bar{u}}{\partial x}+\frac{\partial \bar{v}}{\partial y}\right)-\frac{t_{c}+t_{f}}{2}\left\{v\left(\frac{\partial \gamma_{x z}}{\partial x}-\frac{\partial^{2} \bar{w}}{\partial x^{2}}\right)+\left(\frac{\partial \gamma_{y z}}{\partial y}-\frac{\partial^{2} \bar{w}}{\partial y^{2}}\right)\right\}\right]
\end{aligned}
$$

여기서, $\sigma_{x 1}$ 과 $\sigma_{y 1}$ 은 Fig. 3 에서 보는 바와 같이, $z<0$ 인 위치에 있는 면재에서의 길이방향과 폭방향의 축응력이고, $\sigma_{x 2}$ 과 $\sigma_{y 2}$ 은 $z>0$ 인 위치에 있는 면재에서의 길이방향과 폭방향의 축응력이 다. 횡압력 $p$ 가 $z$ 축의 양의 방향으로 작용하면, 횡압력에 의해 $\sigma_{x 1}$ 과 $\sigma_{y 1}$ 는 압축, $\sigma_{x 2}$ 과 $\sigma_{y 2}$ 은 인장 응력상태가 된다.

\section{3. 최종강도 설계식 도출개발}

저자는 횡압력과 면내압축 하중의 조합하중을 받는 경계조건 이 단순지지인 샌드위치 패널의 최종강도 설계식을 선행연구를 통해 도출한 바가 있다. 먼저 비선형 유한요소 해석기법을 활용 하여 작용 하중의 증가에 따른 샌드위치 패널의 탄소성 붕괴거 동 특성을 분석하여, 면재의 축응력을 기준으로 최종강도 설계 식을 도출하였다. 패널의 경계가 단순지지 조건인 경우에는, 횡 압력에 의해 압축응력이 발생하는 면재 중심에서 시작된 소성 화가 경계쪽으로 확산되어 면내 하중이 작용하지 않는 모서리 의 가운데에 소성화가 발생하면 최종강도에 도달함을 비선형 유한요소 해석결과를 통해 분석하여 규명하였고, 해석적으로 도출한 면재의 축응력과 von Mises 항복조건을 활용하여 최종 강도 설계식을 정의하여 그 적용성을 확인하였다(Kim and Hughes, 2005).

\section{1 고정단 경계조건을 갖는 샌드위치 패널의 탄소성 붕괴거동 특성}

Table 1의 샌드위치 패널을 대상으로 횡압력과 면내압축 하중
의 조합하중을 받는 고정단 경계조건의 샌드위치 패널에 대한 탄소성 붕괴거동 특성을 비선형 유한요소 해석기법을 사용하여 분석하였다. 사용된 유한요소해석 모델은 Fig. 4와 같다. 선행연 구에서 얻은 경험과 Riber(1997)가 강조한 경계부근의 횡처짐과 변형률을 잘 묘사하기 위해서 요소의 크기가 $100 \mathrm{~mm}$ 정도가 되 도록 하였고, 경계주변에서는 약 $50 \mathrm{~mm}$ 정도가 되도록 요소를 분 할하였다. 사용한 요소는 4절점 적층 쉘요소(4-node layered shell element)로 대상 샌드위치 패널을 2626개의 요소로 분할하고 심 재, 면재 그리고 심재로 구성되는 3 개의 층으로 구성하였다. 심 재와 면재는 모두 등방성 재료이며 면재는 탄성-완전소성체 (Elastic-perfectly plastic material)로, 심재는 탄성체로 모델링하였 으며 최종강도를 구하기 위해서 상용코드 ANSYS를 사용하여 탄소성 대변형해석을 수행하였다(ANSYS, 1999).

경계조건은 Fig. 4에 보는 바와 같이 패널 모서리에 위치한 각 절점(Node)의 자유도를 0 으로 설정하여 고정단 경계조건을 설정 하였다. 즉, 식 (13)-(14)와 같이 $x=-a / 2, a / 2$ 위치의 절점들은 $z$ 방향(횡처짐 방향)의 직선 변위와 $y$ 방향의 회전 변위가 0 이고, $y=-b / 2, b / 2$ 에서는 $z$ 방향의 직선 변위와 $x$ 방향의 회전 변위가 0 이다. 그리고 패널의 모서리는 패널에 횡처짐이 발생하더라도 직 선을 유지한다고 가정하였다. 이는 대상 패널이 선박 및 해양플랜 트설비의 보강판과 같이 연속된 구조이므로 경계면은 또 다른 패 널로 연결되어 있음을 고려하고 있다(Paik, 2018).

하중조건은 횡압력을 증분시켜서 $0.3 \mathrm{~N} / \mathrm{mm}^{2}$ 이 되도록 약 20 단계 를 거쳐 서서히 증분되도록 해석을 수행한 후 면내압축 하중을 Arc-length법으로 증분시키며 최종강도를 구하였다. 이 때 강체 운

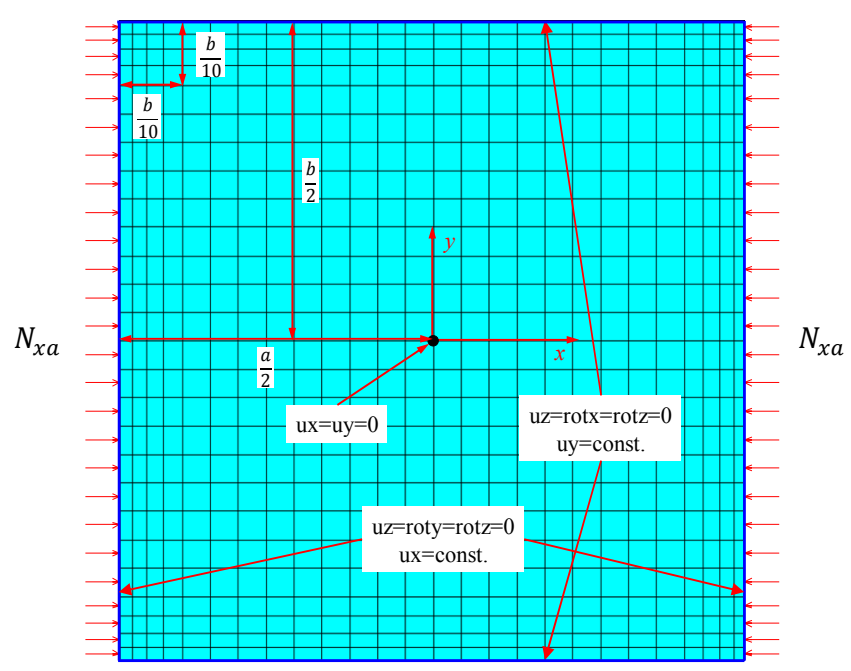

Fig. 4 Finite element modeling for retangular sandwich panels under in-plane compression and lateral pressure with clamped edges

Table 1 Investigated sandwich panels for the collapse behavior under in-plane edge compression and lateral pressure

\begin{tabular}{ccccccccccc}
\hline \hline \multirow{2}{*}{$\begin{array}{c}a \\
{[\mathrm{~mm}]}\end{array}$} & $\begin{array}{c}b \\
{[\mathrm{~mm}]}\end{array}$ & $\begin{array}{c}t_{p} \\
{[\mathrm{~mm}]}\end{array}$ & $\begin{array}{c}E \\
{[\mathrm{GPa}]}\end{array}$ & $v$ & $\begin{array}{c}\sigma_{Y} \\
{[\mathrm{MPa}]}\end{array}$ & $\begin{array}{c}t_{c} \\
{[\mathrm{~mm}]}\end{array}$ & $\begin{array}{c}E_{c} \\
{[\mathrm{MPa}]}\end{array}$ & $v_{c}$ & $p$ \\
\hline 2400 & 2400 & 6 & 206 & 0.3 & 352.8 & 40 & 750 & 0.36 & 0.3 \\
2400 & 2400 & 6 & 206 & 0.3 & 352.8 & 60 & 750 & 0.36 & 0.3 \\
\hline
\end{tabular}




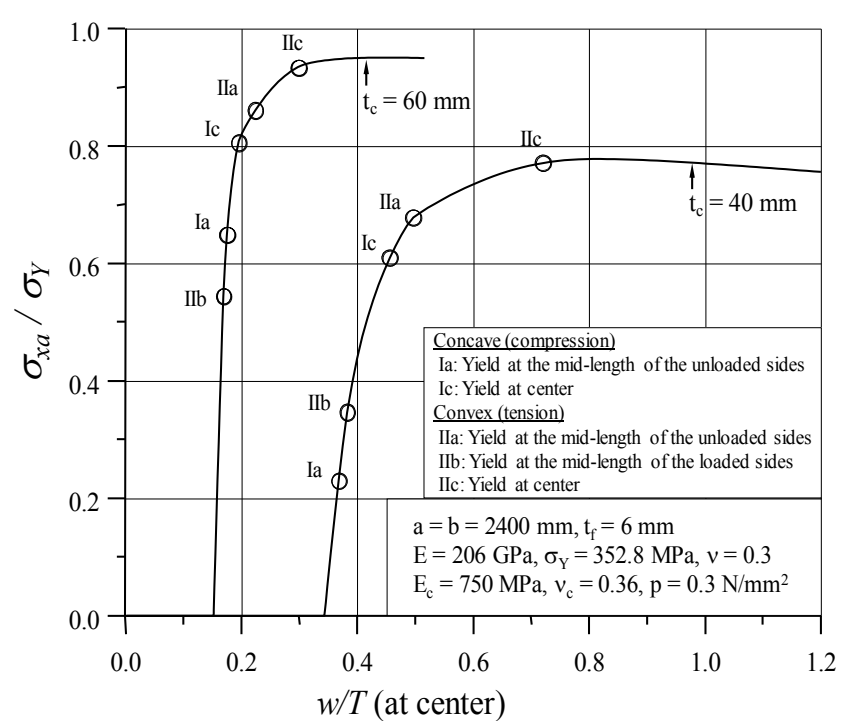

Fig. 5 The collapse behavior of sandwich panels under in-plane edge compression and lateral pressure with clamped edges

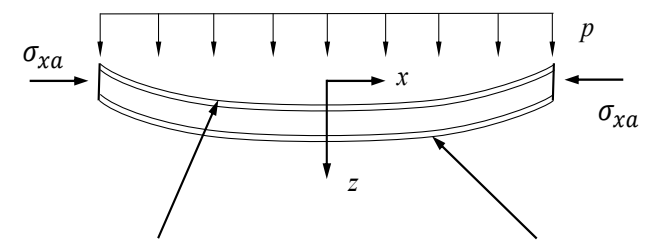

Face plate I (Concave)

Face plate II (Convex)

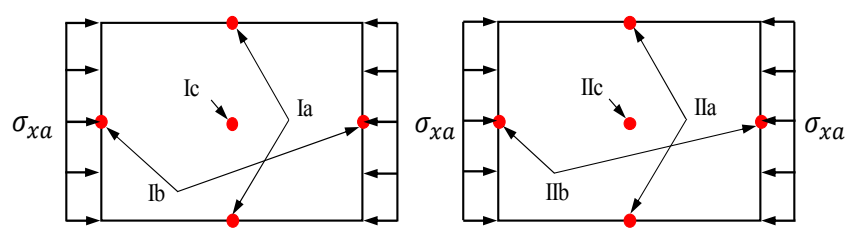

Fig. 6 A schematics diagram of progressive yielding of the face plates of sandwich panels under in-plane edge compression and lateral pressure with clamped edges

동(Rigid body motion)으로 해석이 발산하는 것을 방지하기 위해 패널 중앙의 1 개 절점에서 $x, y$ 방향의 직선 변위를 0 으로 그리고 모서리에 모든 절점에서 방향의 회전 변위를 0 으로 설정하였다.

Fig. 5는 횡압력과 면내압축 하중의 조합하중을 받는 고정단 경계조건의 샌드위치 패널의 탄소성 붕괴거동 특성을 보여주고 있다. 가로축은 패널의 중앙에서 발생하는 최대 횡처짐량 $(w)$ 을 패널의 총두께 $\left(T=2 t_{f}+t_{c}\right)$ 로 무차원하여, 세로축은 작용한 면내 압축 하중을 면재의 항복강도로 무차원하여 도식화하고 있다. 두 패널 모두 동일한 횡압력을 받고 있지만 굽힘강성이 작은 $t_{c}=40 \mathrm{~mm}$ 인 패널에서 횡처짐량이 더 크게 발생하고, 면내압축 하중이 증가할수록 $t_{c}=40 \mathrm{~mm}$ 인 패널에서 횡처짐량이 더 크게 발생한다. 두 패널의 최종강도는 각각 $0.950,0.778$ 로 $t_{c}=40 \mathrm{~mm}$ 인 패널이 낮음을 확인할 수 있었다.

최종강도에 도달하기까지 면재의 점진적 소성화(Progressive yielding) 패턴을 살펴보기 위해서 Fig. 6에 표시된 위치, 즉 횡압력 에 의해서 압축이 발생하는 면재(Concave)의 면내 하중이 작용하
지 않는 모서리의 가운데 부분(Ia), 면내 하중이 작용하는 모서리 의 가운데 부분 $(I b)$ 와 면재의 중앙부분 $(I c)$ 와 횡압력에 의해서 인 장이 발생하는 면재(Convex)의 면내 하중이 작용하지 않는 모서리 의 가운데 부분 $(I I a)$, 면내 하중이 작용하는 모서리의 가운데 부분 (IIb), 면재의 중앙부분(IIc)에서 소성화 발생을 조사하였다. Fig. 5 에서 보는 바와 같이 $t_{c}=40 \mathrm{~mm}$ 인 경우, Ia-IIb-Ic-IIa-IIc 의 순서로 소성화가 진전되며, $t_{c}=60 \mathrm{~mm}$ 인 경우, $I I b-I a-I c-I I a-I I c$ 의 순서로 소성화가 진전됨을 알 수 있었다. 그리고 두 경우 모두 Ic-IIa-IIc의 순서로 소성화가 진행되며 샌드위치 패널은 횡압력에 의해서 인 장이 발생하는 면재(Convex)의 중앙부분(IIc)에서 소성화가 발생 하면 최종강도에 도달함을 확인할 수 있었다. Fig. 7-8은 본 연구에 서 수행한 비선형 유한요소 해석결과로 각각 $t_{c}=40,60 \mathrm{~mm}$ 인 샌드위치 패널에 대한 등가응력(von Mises equivalent stress) 분포 를 보여주고 있으며 상기에서 설명한 전진적 소성화 패턴을 살펴 볼 수 있도록 Ic-IIa-IIc의 순서로 정리하였다.

3.2 고정단 경계조건을 갖는 샌드위치 패널의 최종강도 설계식 2.3절에서 구한 샌드위치 패널의 이론해석식을 활용하면 면재 중앙부분에서 발생하는 축응력 성분을 쉽게 구할 수가 있다. 즉, 식 (16)-(20)과 식 (22)-(25)를 사용하면 샌드위치 패널의 면 재 중앙부분 $(x=0, y=0)$ 에서의 축응력을 식 (26)-(29)과 같이 구 할 수가 있다.

$$
\begin{aligned}
& \sigma_{x 1}=-\frac{N_{x a}}{2 t_{f}}+\frac{E\left(t_{c}+t_{f}\right)}{2\left(1-v^{2}\right)}\left\{\frac{16 a_{1}}{a^{2}}-\frac{8 a_{2}}{a^{2}}+\frac{2 a_{6}}{a}+v\left(\frac{16 a_{1}}{b^{2}}-\frac{8 a_{3}}{b^{2}}+\frac{2 a_{7}}{b}\right)\right\} \\
& \sigma_{y 1}=\frac{E\left(t_{c}+t_{f}\right)}{2\left(1-v^{2}\right)}\left\{\frac{16 a_{1}}{b^{2}}-\frac{8 a_{3}}{b^{2}}+\frac{2 a_{7}}{b}+v\left(\frac{16 a_{1}}{a^{2}}-\frac{8 a_{2}}{a^{2}}+\frac{2 a_{6}}{a}\right)\right\} \\
& \sigma_{x 2}=-\frac{N_{x a}}{2 t_{f}}-\frac{E\left(t_{c}+t_{f}\right)}{2\left(1-v^{2}\right)}\left\{\frac{16 a_{1}}{a^{2}}-\frac{8 a_{2}}{a^{2}}+\frac{2 a_{6}}{a}+v\left(\frac{16 a_{1}}{b^{2}}-\frac{8 a_{3}}{b^{2}}+\frac{2 a_{7}}{b}\right)\right\} \\
& \sigma_{y 2}=-\frac{E\left(t_{c}+t_{f}\right)}{2\left(1-v^{2}\right)}\left\{\frac{16 a_{1}}{b^{2}}-\frac{8 a_{3}}{b^{2}}+\frac{2 a_{7}}{b}+v\left(\frac{16 a_{1}}{a^{2}}-\frac{8 a_{2}}{a^{2}}+\frac{2 a_{6}}{a}\right)\right\}
\end{aligned}
$$

여기서, 는 전술한 바와 같이 부록에 정리된 연립방정식을 풀면 구해지는 횡처짐의 크기와 면외전단 변형률의 크기로써 작용한 하중 즉, $p$ 와 $N_{x a}\left(=\sigma_{x a} \times 2 t_{f}\right)$ 에 따라 그 크기가 증가하며, 이에 따라 식 (26)-(29)의 축응력도 증가하게 된다. 그리고 패널은 횡 압력에 의해서 인장이 발생하는 면재(Convex)의 중앙부분에서 소성화가 발생할 때 최종강도가 되므로 von Mises 항복조건을 활용하여 식 (30)과 같이 최종강도 설계식을 도출할 수 있다. 즉, $p$ 가 $z$ 축의 양의 방향으로 작용하면, 횡압력에 의해 $\sigma_{x 1}$ 과 $\sigma_{y 1}$ 는 압축, $\sigma_{x 2}$ 과 $\sigma_{y 2}$ 은 인장 응력상태가 되므로 $\sigma_{x 1}$ 과 $\sigma_{y 1}$ 이 식 (30) 을 만족하는 $N_{x a}$ 가 샌드위치 패널의 최종강도가 된다.

$$
\sigma_{Y}=\sqrt{\sigma_{x i}^{2}-\sigma_{x i} \sigma_{y i}+\sigma_{y i}^{2}}
$$

여기서, $\sigma_{Y}$ 는 면재의 항복강도다. 


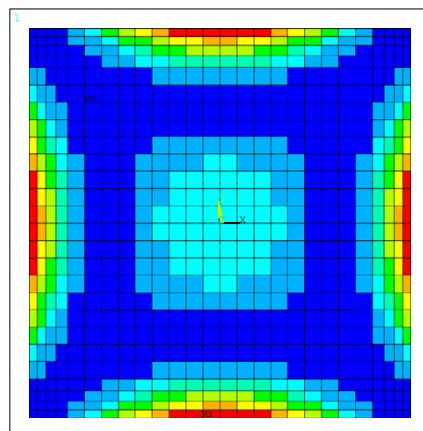

Face plate I (Concave)

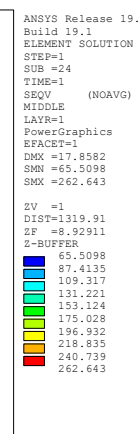

(a) $p=0.3 \mathrm{~N} / \mathrm{mm}^{2}, \sigma_{x a} / \sigma_{Y}=0.0$

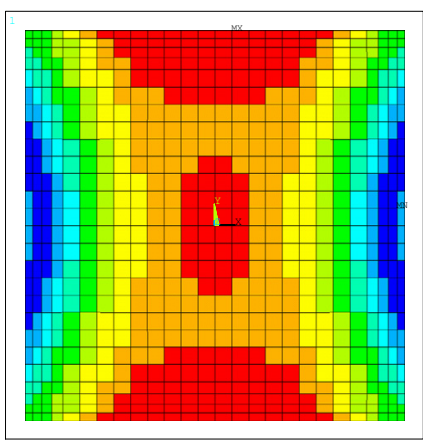

Face plate I (Concave)

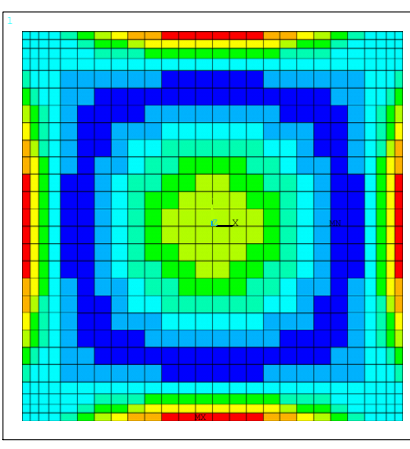

Face plate II (Convex)

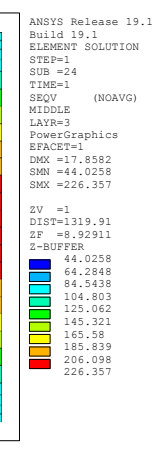

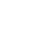
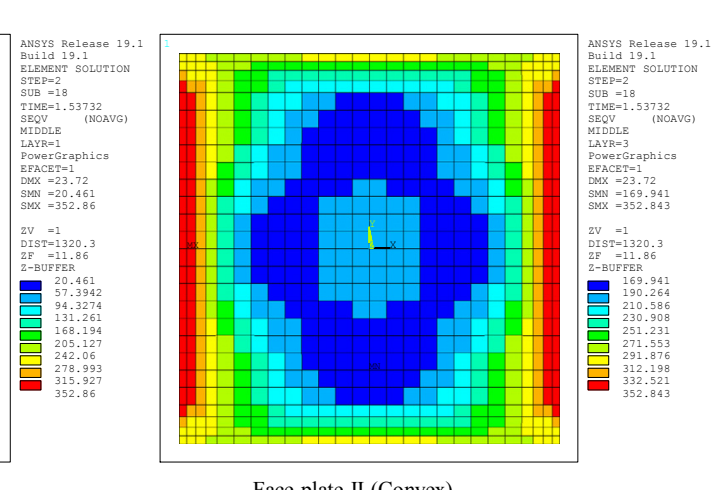

(b) $p=0.3 \mathrm{~N} / \mathrm{mm}^{2}, \sigma_{x a} / \sigma_{y}=0.61$

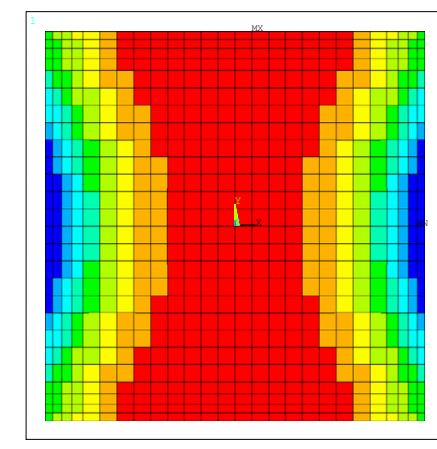

Face plate I (Concave)

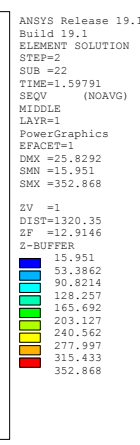

(c) $p=0.3 \mathrm{~N} / \mathrm{mm}^{2}, \sigma_{x a} / \sigma_{Y}=0.68$

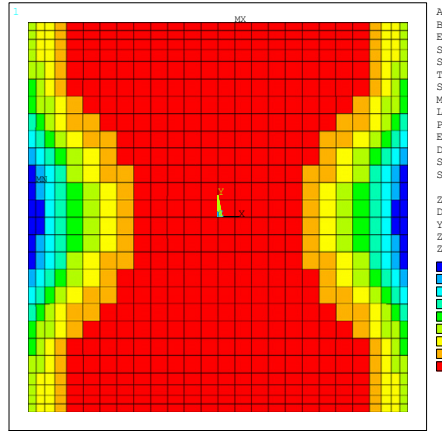

Face plate I (Concave)

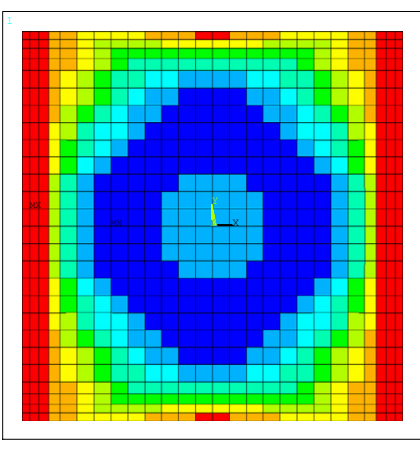

Face plate II (Convex)

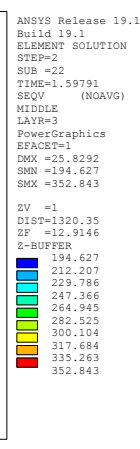$$
\text { . }
$$ 
Analytical Solution for the Ultimate Strength of Sandwich Panels under In-plane Compression and Lateral Pressure 541

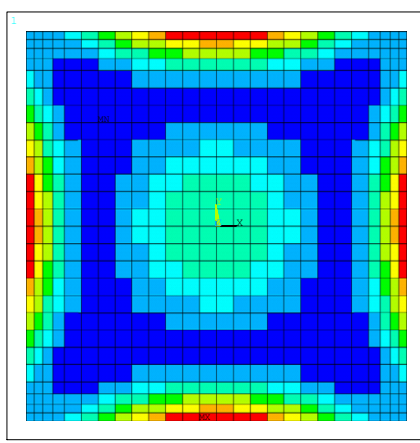

Face plate I (Concave)

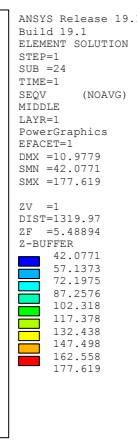

(a) $p=0.3 \mathrm{~N} / \mathrm{mm}^{2}, \sigma_{x a} / \sigma_{Y}=0.0$

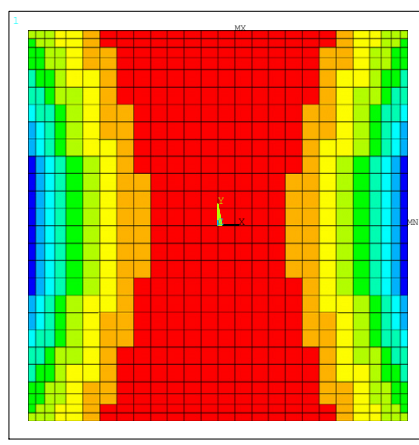

Face plate I (Concave)

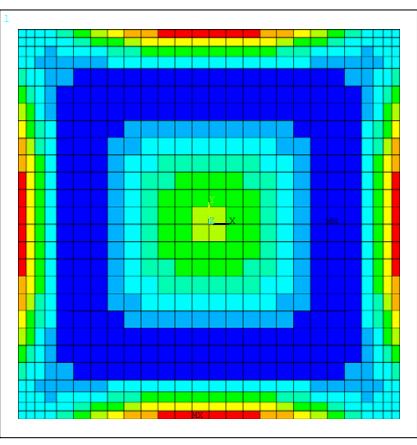

Face plate II (Convex)

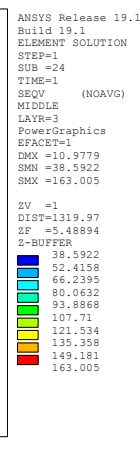$$
\text { (1) }
$$

(b) $p=0.3 \mathrm{~N} / \mathrm{mm}^{2}, \sigma_{x a} / \sigma_{Y}=0.81$

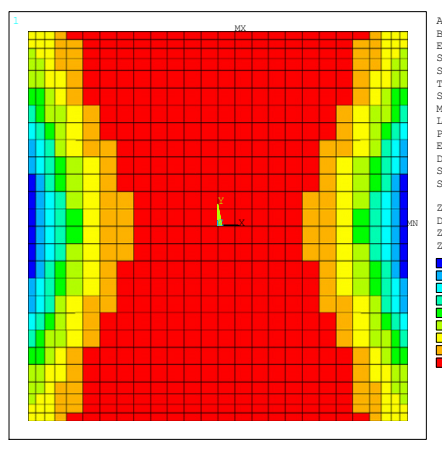

Face plate I (Concave)
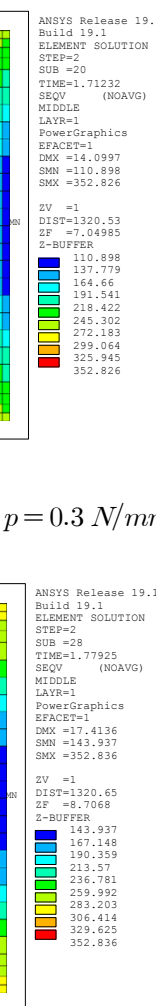

(c) $p=0.3 \mathrm{~N} / \mathrm{mm}^{2}, \sigma_{x a} / \sigma_{Y}=0.88$

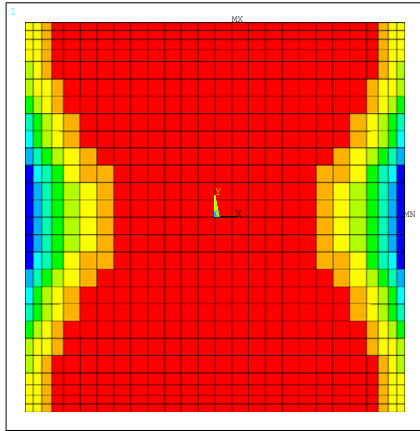

Face plate I (Concave)

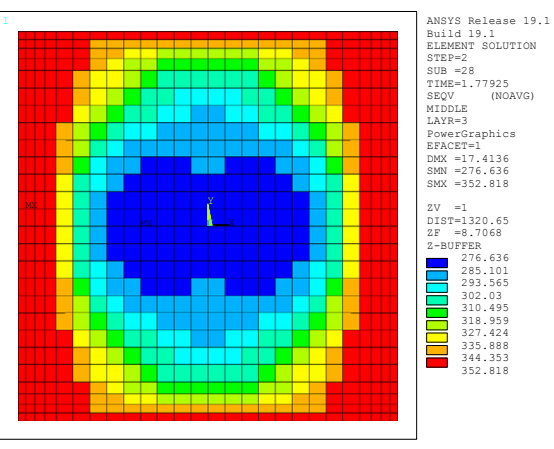

Face plate II (Convex)

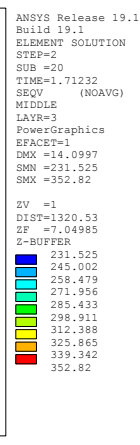

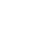

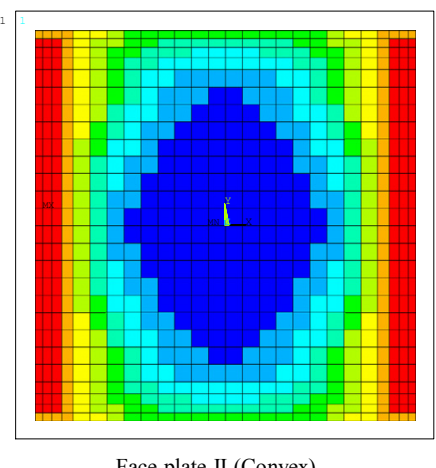




\section{4. 최종강도 설계식의 적용성 검증}

본 장에서는 3.2절에서 도출한 횡압력과 면내압축 하중의 조 합하중을 받는 고정단 경계조건을 갖는 샌드위치 패널의 최종 강도 설계식, 즉 식 (30)의 적용 가능성을 검증하기 비선형 유한 요소해석을 수행하였다. 대상 샌드위치 패널은 Table 2정리되어 있으며, 심재와 면재의 재료물성치 $\left(E, v, \sigma_{Y}, E_{c}, v_{c}\right)$ 는 Table 1 과 같다. 비선형 유한요소해석은 3.1절에서 설명한 방법과 동일 한 방법으로 수행하되었으며, 대상패널의 $a / b$ 가 1.0 인 경우 $26 \times 26$ 개, $a / b$ 가 3.0 인 경우 $72 \times 26$ 개의 요소를 사용하여 분할하 였다.

3.2절에서 도출한 최종강도 설계식으로 대상 패널의 최종강도 를 계산하기 위해서는 패널의 주요 치수와 작용하중 $p$ 와 $N_{x a}$ 을 부록에 정리된 연립방정식에 대입하여 연립방정식의 해 $\left(a_{i}\right)$ 를 구하고, 식 (26)-(29)를 사용하여 횡압력에 의해서 인장이 발생 하는 면재 중앙부분의 축응력을 구하여 식 (30)이 만족하는 면

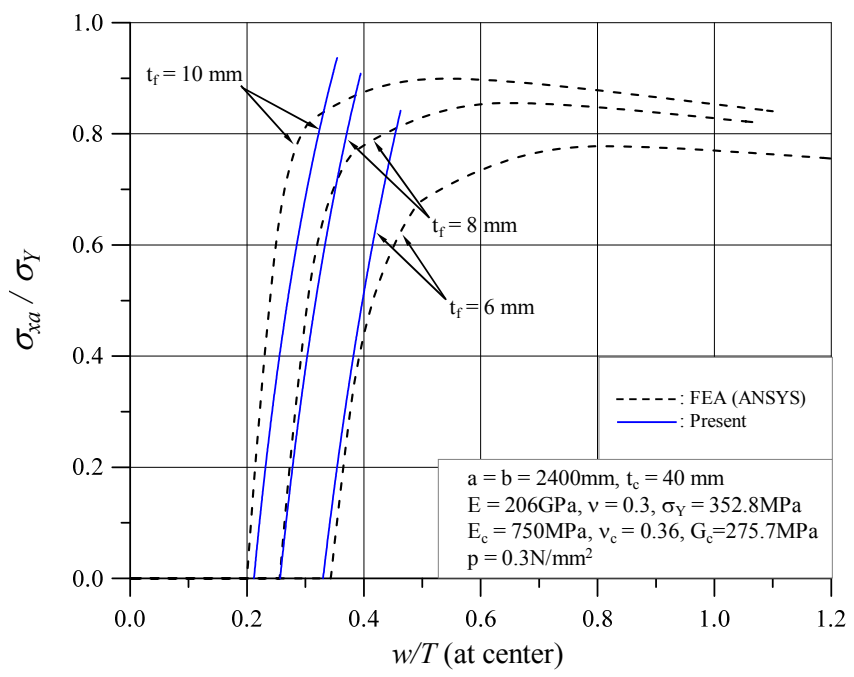

(a) $t_{c}=40 \mathrm{~mm}$
내압축 하중 $\left(N_{x a}\right)$ 을 구하였다. 식 (30)을 만족하는 면내압축 하 중을 찾기 위해서는 $N_{x a}$ 를 일정 간격으로 계속 증분시키거나, 뉴턴 랩슨법(Newton-Raphson method)을 사용하였으며, 연립방정 식의 해는 가우스-요르단 소거법(Gauss-Jordan elimination method) 을 사용하여 구하였다.

Fig. 9는 횡압력을 받고 있는 정사각형 샌드위치 패널에 면내 압축 하중이 추가적으로 가해졌을 때의 처짐거동을 나타내고 있다. 점선은 비선형 유한요소해석 결과이고 실선은 본 연구에 서 도출한 이론해석해의 결과이다. 먼저 비선형 유한요소해석 결과를 살펴보면 심재의 두께가 두꺼운 경우 즉, $t_{c}$ 가 $60 \mathrm{~mm}$ 인 경우의 횡처짐량이 $t_{c}$ 가 $40 \mathrm{~mm}$ 인 경우보다 작음을 알 수 있다. 횡압력 $\left(p=0.3 \mathrm{~N} / \mathrm{mm}^{2}\right)$ 만 작용할 때, 즉 $\sigma_{x a}=0$ 일 때 횡처짐량을 살 펴보면 $t_{f}=10 \mathrm{~mm}$ 인 경우 $t_{c}=40 \mathrm{~mm}$ 일 때 $w / T=0.2, t_{c}=60 \mathrm{~mm}$ 일 때 $w / T=0.1$ 로 $50 \%$ 정도 감소하였고 $t_{f}=6 \mathrm{~mm}$ 인 경우에도 $t_{c}=40 \mathrm{~mm}$ 일 때 $w / T=0.34, t_{c}=60 \mathrm{~mm}$ 일 때 $w / T=0.15$ 로 약 $44 \%$ 정도 감소 하였음을 알 수 있다. 면내하중이 증가함에 따라 횡처짐량은 완

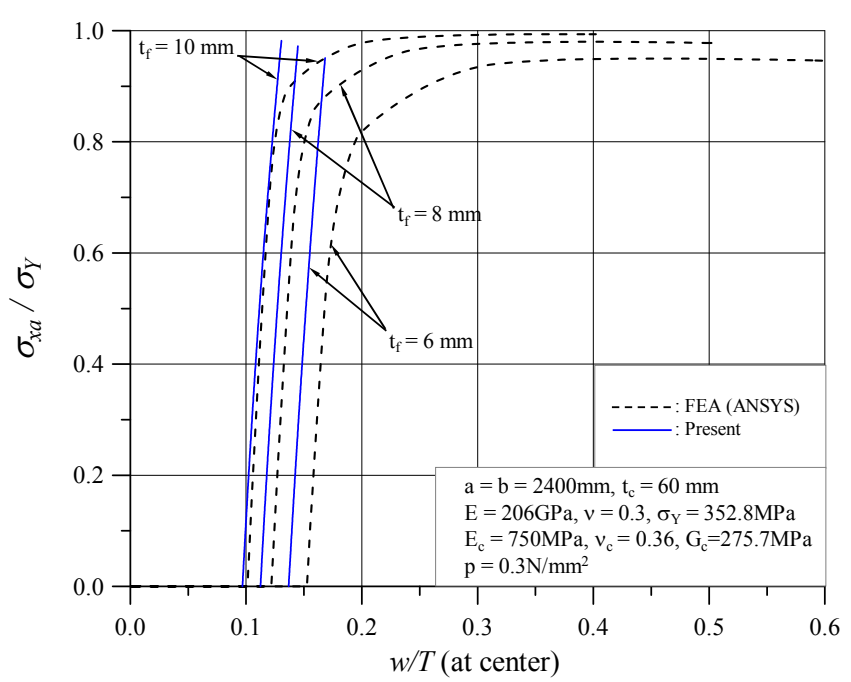

(b) $t_{c}=60 \mathrm{~mm}$

Fig. 9 The ultimate strength comparisons of analytical solutions with FEA results varying $t_{f}\left(t_{c}=\right.$ constant) for sandwich panels under in-plane edge compression and lateral pressure with clamped edges $(a / b=1.0)$

Table 2 Sandwich panels for ultimate strength calculation with ANSYS

\begin{tabular}{|c|c|c|c|c|c|c|}
\hline \multirow{2}{*}{$\begin{array}{c}a \\
{[\mathrm{~mm}]}\end{array}$} & \multirow{2}{*}{$\begin{array}{c}b \\
{[\mathrm{~mm}]}\end{array}$} & \multirow{2}{*}{$\begin{array}{c}t_{p} \\
{[\mathrm{~mm}]}\end{array}$} & \multirow{2}{*}{$\begin{array}{c}t_{c} \\
{[\mathrm{~mm}]}\end{array}$} & \multirow{2}{*}{$\begin{array}{c}p \\
{\left[\mathrm{~N} / \mathrm{mm}^{2}\right]}\end{array}$} & \multicolumn{2}{|c|}{$\sigma_{x u} / \sigma_{Y}$} \\
\hline & & & & & FEA (ANSYS) & Present (Eq. (30)) \\
\hline \multirow{6}{*}{2400} & \multirow{12}{*}{2400} & 6 & 40 & \multirow{12}{*}{0.3} & 0.778 & 0.826 \\
\hline & & 8 & 40 & & 0.855 & 0.893 \\
\hline & & 10 & 40 & & 0.899 & 0.923 \\
\hline & & 6 & 60 & & 0.950 & 0.947 \\
\hline & & 8 & 60 & & 0.980 & 0.969 \\
\hline & & 10 & 60 & & 0.994 & 0.979 \\
\hline \multirow{6}{*}{7200} & & 6 & 40 & & 0.783 & 0.755 \\
\hline & & 8 & 40 & & 0.888 & 0.879 \\
\hline & & 10 & 40 & & 0.933 & 0.929 \\
\hline & & 6 & 60 & & 0.965 & 0.892 \\
\hline & & 8 & 60 & & 0.999 & 0.944 \\
\hline & & 10 & 60 & & 1.011 & 0.966 \\
\hline
\end{tabular}


만하게 증가하다가 3.1절에서 설명한 바와 같이 면재의 소성화 가 진행됨에 따라 횡처짐량은 급격하게 증가하는데 이 경우에 도 심재가 얇은 경우 즉, $t_{c}=40 \mathrm{~mm}$ 인 경우가 보다 큰 횡처짐의 증가를 보여주고 있다.

본 연구에서 도출한 이론해석해로 같은 패널의 처짐거동을 조 사하기 위해서는 전술한 바와 같이 패널의 주요 치수와 작용하중 $p$ 와 $N_{x a}$ 를 부록에 정리된 연립방정식에 대입하여 연립방정식의 해 $\left(a_{i}\right)$ 를 구하여 식 (16)으로 중앙부의 처짐량을 구하면 된다. 이 때 면내압축 하중, $N_{x a}$ 는 일정 간격으로 계속 증분시켰으며 식 (30)의 우변이 $\sigma_{Y}$ 를 넘지 않는 범위에서 횡처짐과 면내압축 하중 을 도시화하였다. 일차전단변형 판이론과 미소처짐이론을 사용 하여 정식화한 식 (16)은 소성화 진전으로 인해 횡처짐이 급격하 게 증가하는 처짐거동을 구현하지는 못하지만 횡압력으로 인해 발생하는 처짐량과 면내압축 하중의 증가에 의해 발생하는 처짐

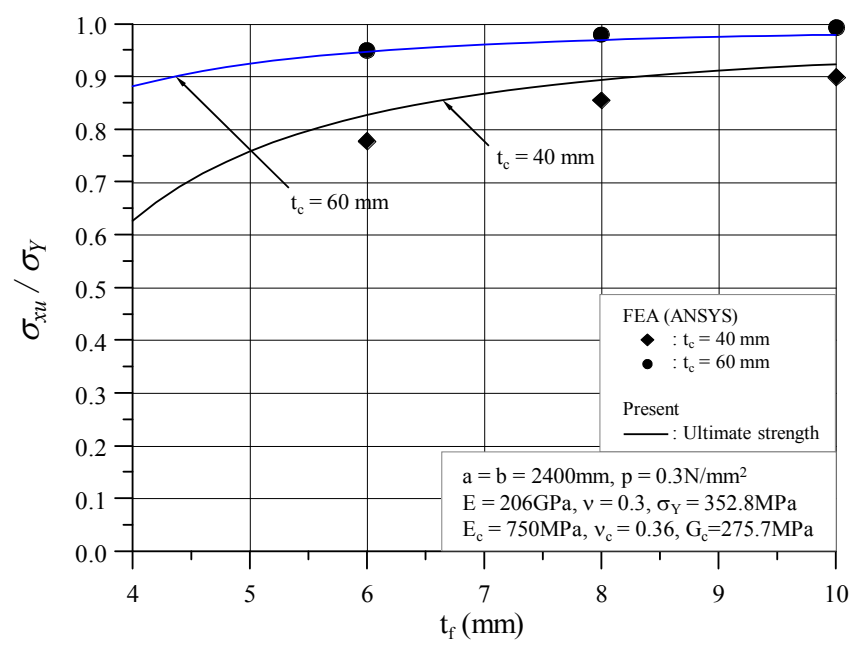

Fig. 10 The ultimate strength comparisons of analytical solutions with FEA results for sandwich panels under in-plane edge compression and lateral pressure with clamped edges $(a / b=1.0)$

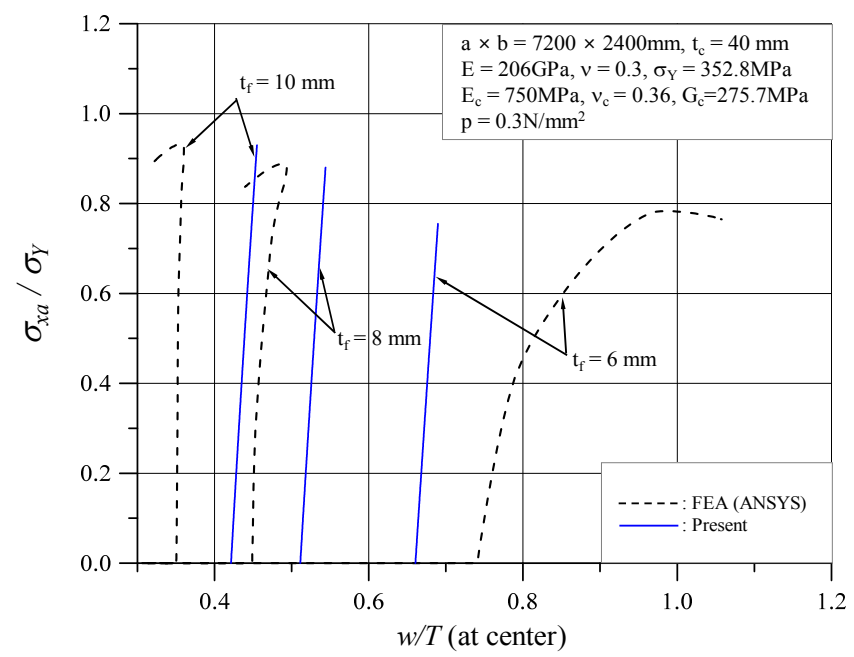

(a) $t_{c}=40 \mathrm{~mm}$
량을 비교적 잘 추정하고 있음을 확인할 수 있다. Table 2에 정리 된 최종강도 결과를 비교해보면 최종강도 설계식으로 구한 최종 강도 역시 $t_{c}=40 \mathrm{~mm}$ 이고 $f_{f}=6 \mathrm{~mm}$ 인 경우 약 $6.2 \%$ 과대 평가하는 경향이 있지만, 비교적 잘 일치함을 확인할 수 있었다.

Fig. 10은 최종강도 설계식을 이용하여 $f_{f}$ 의 변화에 따른 최 종강도 변화를 보여주고 있다. 제안된 최종강도 설계식은 명시 적인 형태의 해석해로 사용이 용이하여 심재 및 면재의 두께 변화에 따른 최종강도 경향을 빠르게 예측할 수 있다. $f_{f}$ 가 증 가할수록 최종강도가 증가하는 경향은 $t_{c}=40 \mathrm{~mm}$ 일때가 더 크다 는 것을 알 수 있으며, 비선형 유한요소해석 결과와 비교했을 때 이러한 경향은 합리적으로 잘 예측하고 있음을 알 수 있다.

Fig. 11는 횡압력을 받고 있는 직사각형 샌드위치 패널 $(a / b$ $=3.0)$ 에 면내압축 하중이 추가적으로 가해졌을 때의 처짐거동을 나타내고 있다. $t_{c}=60 \mathrm{~mm}$ 인 경우에는 비선형 유한요소해석 결과와 이론해석해의 결과가 비교적 일치하고 있지만 $t_{c}=40 \mathrm{~mm}$ 인 경우 는 처짐거동의 오차가 상대적으로 크다는 것을 알 수 있다. 이 는 전술한 바와 같이 패널의 종횡비가 $a / b>2$ 인 경우에는 본 연 구에서 사용한 식 (15)의 다항식 항의 개수가 부족한 것으로 사 료된다. Fig. 12와 Fig. 13에서 보는 바와 같이 $a / b=3$ 인 패널의 횡처짐형상은 $a / b=1$ 인 경우와 상당히 다름을 볼 수 있다. $a / b=3$ 인 경우는 면내압축 하중이 작용하기 이전 횡하중만으로 길이 방향으로 길쭉한 모양의 횡처짐이 발생하고, 면내압축 하중이 작용하면 길쭉한 횡처짐의 모양이 길이방향으로 증가하는데 반 해, $a / b=1$ 인 경우에는 횡하중으로 인해 발생한 횡처짐의 모양은 중앙부분에서는 원형에 가깝고, 면내압축 하중이 작용하면 폭 방향으로 길쭉한 타원형상으로 변하지만 변화가 크지 않다. 그 리고 이러한 횡처짐의 형상은 면내방향의 변위에도 영향이 큰 것으로 보인다. 길이 방향의 면내변위 형상을 살펴보면 $a / b=3$ 인 경우, 횡하중에 의해서 발생한 면내변위 형상은 패널의 모서리 부근에서 길이방향으로 더 길고 급격하게 발생함을 볼 수 있다. 이러한 거동을 고려할 때 $a / b>2$ 인 패널에 대하여 식 (15)의 횡 처짐 변위함수와 식 (19)-(20)의 면외전단 변형률의 변형률함수의

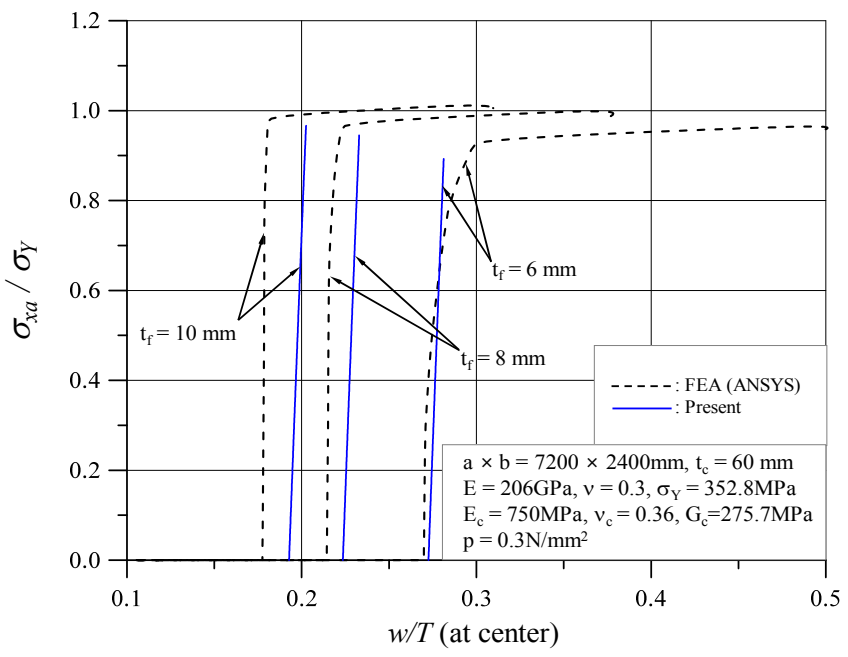

(b) $t_{c}=60 \mathrm{~mm}$

Fig. 11 The ultimate strength comparisons of analytical solutions with FEA results varying $t_{f}\left(t_{c}=\right.$ constant $)$ for sandwich panels under in-plane edge compression and lateral pressure with clamped edges $(a / b=3.0)$ 


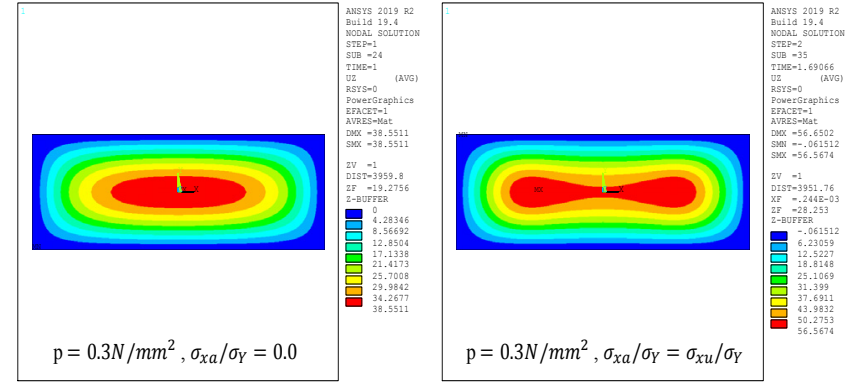

(a) in $z$ direction $(\bar{w})$

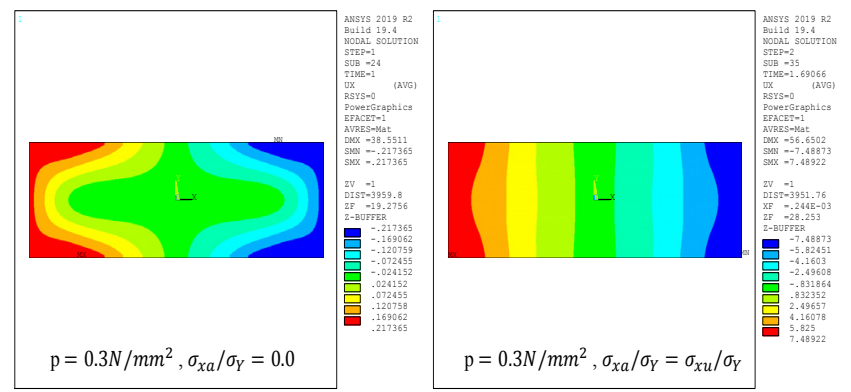

(b) in $x$ direction $(\bar{u})$

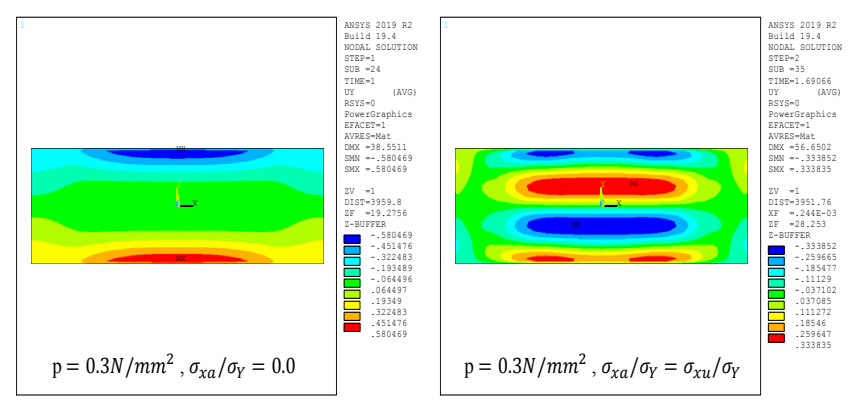

(c) in $y$ direction $(\bar{v})$

Fig. 12 Displacements of the mid-plane of a long sandwich panel $\left(a / b=3.0, t_{c}=40 \mathrm{~mm}, t_{f}=6 \mathrm{~mm}\right)$ with clamped edges

항의 개수를 추가적으로 고려하여 검토할 필요가 있고 이에 대한 추가 연구가 필요할 것으로 사료된다. 그리고 본 연구에서는 대 상 패널이 선박 및 해양플랜트설비의 보강판과 같이 연속된 구 조이므로 경계면은 또 다른 패널로 연결되어 있음을 고려하여 패널의 모서리는 횡처짐이 발생하더라도 직선을 유지한다고 가 정하고 있는데 패널 모서리가 직선을 유지하지 않고 횡처짐으 로 인하여 면내방향으로 변형이 자유롭게 발생하는 경우는 변 형과 응력의 분포가 크게 달라질 것으로 판단되어 상기와 같은 경우에 대한 별도의 연구가 필요하다고 사료된다. Table 2에 정 리된 최종강도 결과를 비교해보면 횡처짐 거동에 오차는 있지 만 최종강도 설계식으로 구한 최종강도는 $t_{c}=60 \mathrm{~mm}$ 이고 $t_{f}$ $=6 \mathrm{~mm}$ 인 경우 약 $7.6 \%$ 과소 평가하는 경향이 있지만, 비교적 잘 일치함을 볼 수 있다.

Fig. 14는 최종강도 설계식을 이용하여 구한 $t_{f}$ 의 변화에 따른 최종강도 변화를 보여주고 있다. $t_{f}$ 가 증가할수록 최종강도가 증가하는 경향은 $t_{c}=40 \mathrm{~mm}$ 일때가 더 크다는 것을 알 수 있으며 비선형 유한요소해석 결과와 비교했을 때 이러한 경향은 합리 적으로 잘 예측하고 있음을 알 수 있다.
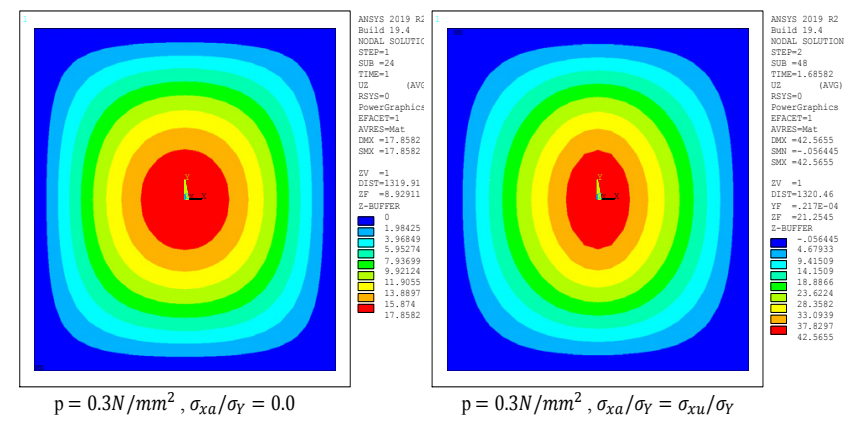

(a) in $z$ direction $(\bar{w})$

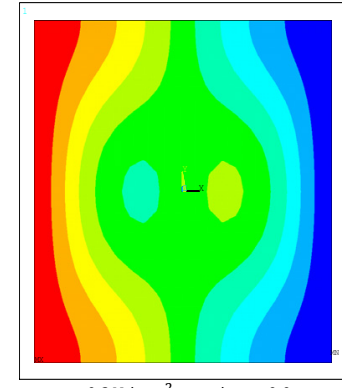

$\mathrm{p}=0.3 \mathrm{~N} / \mathrm{mm}^{2}, \sigma_{x a} / \sigma_{Y}=0.0$

(b) in $x$ direction $(\bar{u})$

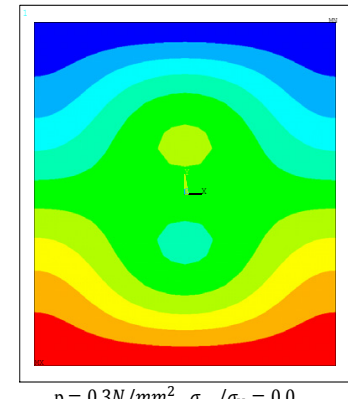

$\mathrm{p}=0.3 \mathrm{~N} / \mathrm{mm}^{2}, \sigma_{x a} / \sigma_{Y}=0.0$
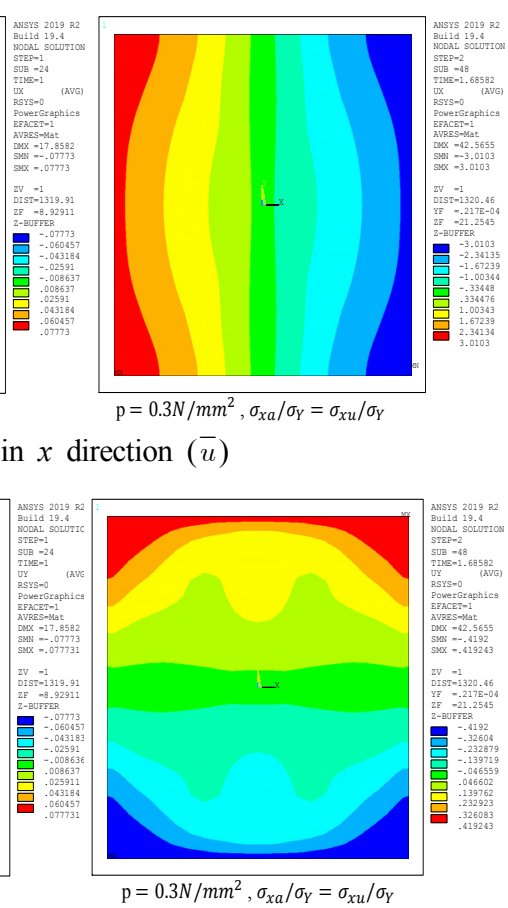

(c) in $y$ direction $(\bar{v})$
Fig. 13 Displacements of the mid-plane of a square sandwich panel $\left(a / b=1.0, t_{c}=40 \mathrm{~mm}, t_{f}=6 \mathrm{~mm}\right)$ with clamped edges

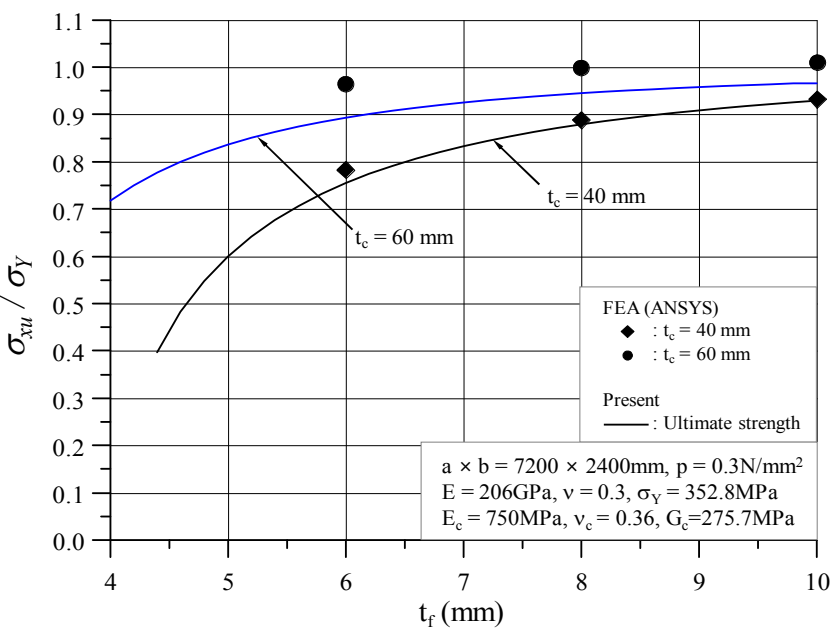

Fig. 14 The ultimate strength comparisons of analytical solutions with FEA results for sandwich panels under in-plane edge compression and lateral pressure with clamped edges $(a / b=3.0)$ 
Analytical Solution for the Ultimate Strength of Sandwich Panels under In-plane Compression and Lateral Pressure 545

\section{5. 결 론}

선박 및 해양플랜트 설비에 적용이 점차 증가되고 있는 샌드 위치 패널 구조의 설계기법을 향상시키기 위해서 본 연구에서 는 횡압력과 면내압축 하중이 동시에 작용하는 직사각형 샌드 위치 패널의 최종강도 예측할 수 있는 설계식을 개발하였다. 회 전이 완전히 구속된 경계조건을 갖는 샌드위치 패널의 거동을 일차전단변형 판이론과 미소처짐이론을 사용하여 정식화하였 고, 최소 포텐셜 에너지 원리 적용하여 샌드위치 패널의 변형과 응력을 구할 수 있는 명시적인 형태의 해석해를 도출하였다. 제 안된 최종강도 설계식은 비선형 유한요소해석 결과 비교하여 적용성을 검토하였으며 그 결과 다음과 같은 식견과 결론을 얻 을 수 있었다.

(1) 횡압력과 면내압축 하중이 동시에 작용하는 직사각형 샌드 위치 패널의 처짐거동은 일차전단변형 판이론과 미소처짐이론을 사용하여 정식화하여 예측할 수 있으며, 패널의 종횡비에 따라 처 짐을 정의하는 변위함수를 적절하게 선정할 필요가 있다.

(2) 샌드위치 패널의 종횡비가 크지 않을 경우 $(a / b \leq 2.0)$ 는, 본 연구에서와 같이 5 개의 미지상수를 갖는 다항식 형태의 변 위함수로 처짐거동을 합리적으로 잘 예측할 수 있으나, $a / b=3.0$ 인 경우에는 처짐거동을 크게 평가하는 경향을 보였다. 이에 대해서는 변위함수에 추가적인 항을 고려할 필요가 있다 고 사료된다.

(3) 횡압력을 받는 샌드위치 패널에 면내압축 하중이 추가적 으로 작용할 경우, 샌드위치 패널의 최종강도는 횡압력에 의해 서 인장이 발생하는 면재(Convex)의 중앙부분에서 소성화가 발 생하는 하중임을 도출된 해석해를 활용하여 정의하고 최종강도 설계식으로 제안하였다.

(4) 제안된 최종강도 설계식은 명시적인 형태의 해석해로 사 용이 용이하여 심재 및 면재의 두께 변화에 따른 최종강도 변 화의 경향을 빠르게 예측할 수 있었다.

(5) 제안된 최종강도 설계식은 비선형 유한요소해석 결과와 비교시 $t_{c}=40 \mathrm{~mm}$ 이고 $t_{f}=6 \mathrm{~mm}$ 인 경우 약 $6.2 \%$ 과대평가하고, $t_{c}$ $=60 \mathrm{~mm}$ 이고 $t_{f}=6 \mathrm{~mm}$ 인 경우 약 $7.6 \%$ 과소평가하였으나 전반적 으로 실용적으로 충분한 결과를 주고있다고 판단된다.

(6) 제안된 설계식은 최종강도를 기준으로 선박 및 해양플랜 트 설비에 샌드위치 패널 구조의 안전성을 평가할 수 있는 설 계기법의 개발에 유용하게 활용될 것으로 사료되며, 횡하중의 크기변화, 패널의 종횡비 및 치수의 변화에 대한 추가적인 적용 성 검증 및 연구가 필요하다고 판단된다.

\section{후기}

이 논문은 부산대학교 기본연구지원사업(2년)에 의하여 연구 되었음

\section{References}

ANSYS, 1999. Theory Reference (Release 5.6). ANSYS Inc., Canonsburg, PA.

DNV-GL, 2016. DNVGL-CG-0154, Steel Sandwich Panel Construction. [Online] Available at: <https://rules.dnvgl.com/docs/pdf/DNVGL/ CG/2016-04/DNVGL-CG-0154.pdf> [Accessed September 2019].

Kim, B.J., Hughes, O.F., 2005. Analytical Solution for the Ultimate Strength of Metal-faced Elastomer-cored Sandwich Panels under In-plane Edge Compression and Lateral Pressure. Journal of Sandwich Structures and Materials, 7(5), 363-394. https://doi.org/ $10.1177 / 1099636205051318$

Lloyd's Register (LR), 2019. Rules for the Application of Sandwich Panel Construction to Ship Structure. Boca Raton, FL.

Mbakogu, F.C., Pavlovic, M.N., 2000. Bending of Clamped Orthotropic Rectangular Plates: a Variational Symbolic Solution. Computers and Structures, 77(2), 117-128. https://doi.org/10. 1016/S0045-7949(99)00217-5

Noor, A.K., Burton, S., Bert, C.W., 1996. Computational Models for Sandwich Panels and Shells. Applied Mechanics Review, 49(3), 155-199. https://doi.org/10.1115/1.3101923

Paik, J.K., 2018. Ultimate Limit State Analysis and Design of Plated Structures. $2^{\text {nd }}$ Edition, John Wiley \& Sons, London.

Plantema, F.J, 1966. Sandwich Construction: The Bending and Buckling of Sandwich Beams, Plates, and Shells. John Wiley \& Sons, London.

Riber, H.J., 1997. Non-linear Analytical Solutions for Laterally Loaded Sandwich Plates. Composite Structures, 39(1-2), 63-83. https:// doi.org/10.1016/S0263-8223(97)00000-7

Reddy, J.N., 2003. Mechanics of Laminated Composite Plates and Shells: Theory and Analysis. $2^{\text {nd }}$ Edition, CRC Press, USA.

Vinson, J.A., 2005. Plate and Panel Structures of Isotropic, Composite and Piezoelectric Materials, Including Sandwich Construction. Springer Netherlands.

SPS Technology, 2019. What is SPS. [Online] Available at: <https:// www.spstechnology.com/what-is-sps $>$ [Accessed September 2019].

Wikipedia, 2019a. Sandwich Panel. [Online] Available at: $<$ https://en. wikipedia.org/wiki/Sandwich_panel> [Accessed September 2019].

Wikipedia, 2019b. Sandwich Plate System. [Online] Available at: $<$ https://en.wikipedia.org/wiki/Sandwich_plate_system $>$ [Accessed September 2019]. 


\section{Appendix}

The seven simultaneous algebraic equations for the coefficients

$$
\left[\begin{array}{lllllll}
C_{11} & C_{12} & C_{13} & C_{14} & C_{15} & C_{16} & C_{17} \\
C_{21} & C_{22} & C_{23} & C_{24} & C_{25} & C_{26} & C_{27} \\
C_{31} & C_{32} & C_{33} & C_{34} & C_{35} & C_{36} & C_{37} \\
C_{41} & C_{42} & C_{43} & C_{44} & C_{45} & C_{46} & C_{47} \\
C_{51} & C_{52} & C_{53} & C_{54} & C_{55} & C_{56} & C_{57} \\
C_{61} & C_{62} & C_{63} & C_{64} & C_{65} & C_{66} & C_{67} \\
C_{71} & C_{72} & C_{73} & C_{74} & C_{75} & C_{76} & C_{77}
\end{array}\right]\left\{\begin{array}{l}
a_{1} \\
a_{2} \\
a_{3} \\
a_{4} \\
a_{5} \\
a_{6} \\
a_{7}
\end{array}\right\}=\left\{\begin{array}{l}
P_{1} \\
P_{2} \\
P_{3} \\
P_{4} \\
P_{5} \\
P_{6} \\
P_{7}
\end{array}\right\}
$$

where, $C_{11}=\frac{131072 b D_{11}}{1575 a^{3}}+\frac{524288 D_{12}}{11025 a b}+\frac{131072 a D_{22}}{1575 b^{3}}+\frac{1048576 D_{66}}{11025 a b}-\frac{65536 b N_{x a}}{33075 a}$,

$$
\begin{aligned}
& C_{12}=\frac{131072 b D_{11}}{11025 a^{3}}+\frac{131072 a D_{22}}{17325 b^{3}} \text {, } \\
& C_{13}=\frac{131072 b D_{11}}{17325 a^{3}}+\frac{131072 a D_{22}}{11025 b^{3}}-\frac{65536 b N_{x a}}{363825 a} \text {, } \\
& C_{14}=\frac{131072 b D_{11}}{33075 a^{3}}-\frac{524288 D_{12}}{363825 a b}+\frac{131072 a D_{22}}{75075 b^{3}}-\frac{1048576 D_{66}}{363825 a b}+\frac{65536 b N_{x a}}{1091475 a} \\
& C_{15}=\frac{131072 b D_{11}}{75075 a^{3}}-\frac{524288 D_{12}}{363825 a b}+\frac{131072 a D_{22}}{33075 b^{3}}-\frac{1048576 D_{66}}{363825 a b}-\frac{65536 b N_{x a}}{1576575 a}, \\
& C_{16}=\frac{65536 b D_{11}}{11025 a^{2}}+\frac{65536 D_{12}}{33075 b}+\frac{131072 D_{66}}{33075 b} \text {, } \\
& C_{17}=\frac{65536 D_{12}}{33075 a}+\frac{65536 a D_{22}}{11025 b^{2}}+\frac{131072 D_{66}}{33075 a} \text {, } \\
& C_{21}=C_{12}, C_{22}=\frac{131072 b D_{11}}{3675 a^{3}}+\frac{524288 D_{12}}{121275 a b}+\frac{131072 a D_{22}}{75075 b^{3}}+\frac{1048576 D_{66}}{121275 a b}-\frac{65536 b N_{x a}}{363825 a} \text {, } \\
& C_{23}=\frac{131072 b D_{11}}{121275 a^{3}}+\frac{131072 a D_{22}}{121275 b^{3}} \text {, } \\
& C_{24}=\frac{6946816 b D_{11}}{363825 a^{3}}+\frac{1048576 D_{12}}{675675 a b}+\frac{131072 a D_{22}}{225225 b^{3}}+\frac{2097152 D_{66}}{675675 a b}-\frac{131072 b N_{x a}}{2027025 a}, \\
& C_{25}=\frac{131072 b D_{11}}{525525 a^{3}}+\frac{131072 a D_{22}}{363825 b^{3}} \text {, } \\
& C_{26}=-\frac{65536 b D_{11}}{33075 a^{2}}-\frac{65536 D_{12}}{363825 b}-\frac{131072 D_{66}}{363825 b}, \\
& C_{27}=\frac{65536 a D_{22}}{121275 b^{2}} \\
& C_{31}=C_{13}, C_{32}=C_{23} \text {, } \\
& C_{33}=\frac{131072 b D_{11}}{75075 a^{3}}+\frac{524288 D_{12}}{121275 a b}+\frac{131072 a D_{22}}{3675 b^{3}}+\frac{1048576 D_{66}}{121275 a b}-\frac{65536 b N_{x a}}{1576575 a}, \\
& C_{34}=\frac{131072 b D_{11}}{363825 a^{3}}+\frac{131072 a D_{22}}{525525 b^{3}}+\frac{65536 b N_{x a}}{12006225 a} \\
& C_{35}=\frac{131072 b D_{11}}{225225 a^{3}}+\frac{1048576 D_{12}}{675675 a b}+\frac{6946816 a D_{22}}{363825 b^{3}}+\frac{2097152 D_{66}}{675675 a b}-\frac{65536 b N_{x a}}{4729725 a}, \\
& C_{36}=\frac{65536 b D_{11}}{121275 a^{2}} \\
& C_{37}=-\frac{65536 D_{12}}{363825 a}-\frac{65536 a D_{22}}{33075 b^{2}}-\frac{131072 D_{66}}{363825 a} \text {, } \\
& C_{41}=C_{14}, C_{42}=C_{24}, C_{43}=C_{34} \text {, } \\
& C_{44}=\frac{84279296 b D_{11}}{4729725 a^{3}}+\frac{524288 D_{12}}{525525 a b}+\frac{131072 a D_{22}}{546975 b^{3}}+\frac{1048576 D_{66}}{525525 a b}-\frac{65536 b N_{x a}}{1576575 a} \text {, } \\
& C_{45}=\frac{131072 b D_{11}}{1576575 a^{3}}+\frac{524288 D_{12}}{12006225 a b}+\frac{131072 a D_{22}}{1576575 b^{3}}+\frac{1048576 D_{66}}{12006225 a b}+\frac{65536 b N_{x a}}{52026975 a} \text {, } \\
& C_{46}=-\frac{65536 b D_{11}}{51975 a^{2}}-\frac{65536 D_{12}}{525525 b}-\frac{131072 D_{66}}{525525 b} \text {, } \\
& C_{47}=-\frac{65536 D_{12}}{1091475 a}+\frac{65536 a D_{22}}{525525 b^{2}}-\frac{131072 D_{66}}{1091475 a} \\
& C_{51}=C_{15}, C_{52}=C_{25}, C_{53}=C_{35}, C_{54}=C_{45} \\
& C_{55}=\frac{131072 b D_{11}}{54675 a^{3}}+\frac{524288 D_{12}}{525525 b}+\frac{84279296 a D_{22}}{4729725 b^{3}}+\frac{1048576 D_{66}}{525525 a b}-\frac{65536 b N_{x a}}{1146475 a} \\
& C_{56}=\frac{65536 b D_{11}}{525525 a^{2}}-\frac{65536 D_{12}}{1091475 b}-\frac{131072 D_{66}}{1091475 b}, \\
& C_{57}=-\frac{65536 D_{12}}{525525 a}-\frac{65536 a D_{22}}{51975 b^{2}}-\frac{131072 D_{66}}{525525 a} \text {, } \\
& C_{61}=C_{16}, C_{62}=C_{26}, C_{63}=C_{36}, C_{64}=C_{46}, C_{65}=C_{56}, \\
& C_{66}=\frac{16384 a b A_{55}}{1091475}+\frac{65536 b D_{11}}{99225 a}+\frac{65536 a D_{66}}{363825 b} \text {, } \\
& C_{67}=\frac{16384 D_{12}}{99225}+\frac{16384 D_{66}}{99225} \text {, } \\
& C_{71}=C_{17}, C_{72}=C_{27}, C_{73}=C_{37}, C_{74}=C_{47}, C_{75}=C_{57}, C_{76}=C_{67} \text {, } \\
& C_{77}=\frac{16384 a b A_{44}}{1091475}+\frac{65536 a D_{22}}{99225 b}+\frac{65536 b D_{66}}{363825 a} \text {, } \\
& P_{1}=-\frac{64 a b p}{225} \text {, } \\
& P_{2}=P_{3}=-\frac{64 a b p}{1575} \text {, } \\
& P_{4}=P_{5}=-\frac{64 a b p}{4725} \text {, } \\
& P_{6}=P_{7}=0
\end{aligned}
$$

